\title{
Capsule commentary on Lo-Ciganic, et al., Trajectories of Diabetes Medication Adherence and Hospitalization Risk: A Retrospective Cohort Study in a Large State Medicaid Program
}

\author{
Michael A. Fischer, MD, MS \\ J Gen Intern Med 31(9):1081 \\ DOI: $10.1007 / \mathrm{s} 11606-016-3765-4$ \\ (c) Society of General Internal Medicine 2016
}

Division of Pharmacoepidemiology and Pharmacoeconomics, Brigham and Women's Hospital and Harvard Medical School, Boston, MA, USA.
$\mathrm{S}$ uccessful treatment of chronic disease often requires patients to take daily medications for many years or a lifetime. But patients struggle to adhere to prescribed medications. Prior research has shown that about half of patients stop taking chronic medications within a year ${ }^{1}$ - if they start taking them at all. ${ }^{2}$

While many studies have demonstrated the prevalence of non-adherence, have explored predictors of the phenomenon, and tested interventions to increase adherence, ${ }^{3}$ our measurement and understanding of adherence remain relatively crude. Adherence is commonly measured using pharmacydispensing records or insurance claims to measure the number of pills or tablets dispensed in a given time interval. Such measures provide insight into the extent to which patients remain on prescribed medications, but do little to discriminate among a range of possible behaviors, such as whether a patient stops a medication soon after initiation then resumes later, adheres intermittently over an extended period, or other idiosyncratic patterns that individuals may adopt.

Recognizing these limitations, researchers have recently applied a novel analytic technique to medication adherencetrajectory models. ${ }^{4}$ By identifying patterns of adherence, these models provide more clinically intuitive measures of how patients are taking medication. The question now is whether these models can provide a better understanding of the predictors or consequences of adherence and thus support more successful interventions to promote medication adherence.

The study by Lo-Ciganic ${ }^{5}$ helps move our understanding forward. They identified seven different patterns of adherence to diabetes medications and found that three patterns of imperfect adherence, when compared to a perfect adherence trajectory, were associated with significantly higher rates of emergency department (ED) visits and hospitalization for diabetes. Use of this approach improved the ability of multivariable models to predict $\mathrm{ED}$ visits or hospitalizations, as measured by the model C-statistic.

The question now is whether trajectory models like those used by Lo-Ciganic can lead to more effective approaches to address adherence. Ideally, trajectory models can identify inflection points in patients' medication-taking behavior when timely interventions to help patients remain on beneficial medications would be especially effective. Developing as well as assessing such interventions is the next key challenge for clinicians and researchers.

Corresponding Author: Michael A. Fischer, MD, MS; Division of Pharmacoepidemiology and PharmacoeconomicsBrigham and Women's Hospital and Harvard Medical School, Boston, MA 02120, USA (e-mail: mfischer@partners.org).

\section{Compliance with ethical standards:}

Conflict of Interest: Dr. Fischer has received research funding through his institution from CVS-Caremark and Otsuka America for studies of medication adherence.

\section{REFERENCES}

1. Benner JS, Glynn RJ, Mogun H, et al. Long-term persistence in use of statin therapy in elderly patients. JAMA. 2002;288(4):455-61.

2. Fischer MA, Stedman MR, Lii J, et al. Primary medication non-adherence: analysis of 195,930 electronic prescriptions. J Gen Intern Med. 2010;25(4):284-90.

3. Cutrona SL, Choudhry NK, Fischer MA, et al. Targeting cardiovascular medication adherence interventions. J Am Pharm Assoc. 2012;52(3):38197.

4. Franklin JM, Shrank WH, Pakes J, et al. Group-based trajectory models: a new approach to classifying and predicting long-term medication adherence. Med Care. 2013;51(9):789-96.

5. Lo-Ciganic W, Donohue JM, Jones BL, et al. Trajectories of diabetes medication adherence and hospitalization risk: a retrospective cohort study in a large state medicaid program. J Gen Intern Med. 2016. doi:10.1007/ s11606-016-3747-6. 